\title{
SURFACE WAVE MAGNITUDES OF SOME NEW ZEALAND EARTHQUAKES 1901-1988
}

\author{
D.J. Dowrick ${ }^{1}$ and E. G. C. Smith²
}

\begin{abstract}
This paper gives a list of magnitudes on the surface wave scale for a selection of larger New Zealand earthquakes that occurred in the period 1901-1988. Most of the events considered were of shallow origin h $<45 \mathrm{~km}$, and the magnitudes ranged from about 5 to 7.8. The Analysis of Variance method of statistical analysis was used to correct the large set of station observations so as to provide consistent mean magnitudes for each event. The resulting station terms and standard errors are given. Comparisons made between the results of this study and the relatively few previous $M_{s}$ determinations show little change except for one or two important events. In particular the magnitude of the 1968 Inangahua earthquake was found to be $7.4( \pm 0.07)$, which is somewhat greater than previous estimates.
\end{abstract}

\section{INTRODUCTION}

The need to redetermine the magnitudes of New Zealand's larger earthquakes on a consistent basis has been apparent for some time. Previously published catalogues containing New Zealand earthquakes [1-4] give magnitudes determined on a variety of bases $\left(M_{L}, m_{b}, M_{s}\right)$, and those bases were not always specified.

Sometimes there are significant discrepancies between the magnitudes quoted by different authors for the same event, and sometimes a reasonably determined magnitude has never been published. For example, the 1922 December 25 and 1932 May 5 events were both listed by Gutenberg and Richter [1] as being of magnitude 6-7.5.

Clearly the above situation was unsatisfactory and it was decided to determine, on a consistent basis, the magnitudes of a selection of local earthquakes, using the surface wave scale. The overall study was conducted by the senior author of this paper, as described in full elsewhere [5]. In the present paper we describe the data that were gathered, the basic $M_{s}$ determination, the statistical analysis used to resolve the individual station $\mathrm{M}_{\mathrm{s}}$ values into robust corrected mean values, and the associated standard errors. We also make comparisons with selected previous $M_{s}$ determinations, and briefly discuss some of the more significant findings.

1. Physics and Engineering Laboratory, DSIR

2. Geophysics Division, DSIR

\section{THE DATA}

The starting point for selecting a list of earthquakes to be studied was the list compiled by Smith [3] having a selection of events of magnitude c.5.0 and greater during the period 1921 to 1974 . This list was supplemented with further events from Smith and Berryman [4] and elsewhere so as to include a range of larger events that have occurred since instrumental surface wave recording got under way around the turn of the century.

The list is thought to be at best complete only for magnitudes of $M_{s} \geq 6.9$, but for magnitudes below this level a primary motivation for selection was to at least include all those events for which felt intensity isoseismal maps were available, together with some others of particular seismological interest.

As described in the next section, $M_{s}$ is determined from the amplitude, $A$, and period, $T$, of the surface waves as recorded by seismographs located at stations all around the world. Data collection consisted of finding as many $(A / T)$ pairs of the chosen events at as many stations as could be cost-effectively searched. Data were obtained from many stations, of which 81 stations proved useable in our statistical analysis. Data were obtained mainly from station bulletins, plus international bulletins, or readings were made directly from the original seismograms. The number of observations found for individual events varied enormously. The number per event that were usable in our statistical analysis, ranged from 2 to 22 , depending on the magnitude, depth and year of the event. 


\section{SURFACE WAVE MAGNITUDE CALCULATION}

The values of $M_{s}$ determined from surface waves recorded at any given station were calculated by two formulae, depending on the type of seismograph that had made the recording.

Firstly, for certain of the earlier events on the list, valuable data were recorded on undamped Milne seismographs at various stations. For these $\mathrm{M}_{s}$ was calculated for each observation using the expression found by Ambraseys [6],

$$
M_{S}=\log \left(2 A_{t}\right)+1.25 \log (D)+4.06
$$

in which $\left(2 A_{t}\right)$ is the double trace amplitude (peak-to-peak) in millimetres, $D$ is the epicentral distance (event to station) in degrees.

Secondly, for data recorded by post-Milne damped seismographs, $M_{s}$ was calculated for each observation using the expression commonly known as the "Prague formula" [7],

$$
M_{\mathrm{S}}=\log (A / T)_{\max }+1.66 \log (D)+3.3
$$

in which $(A / T)_{\max }$ is the maximum ratio of the ground amplitude, $A$, of the surface waves in micrometres, and $T$, the associated period in seconds. $D$ is the epicentral distance in degrees. This formula is now used by the US National Earthquake Information Service and the International seismological centre in the routine reporting of global seismicity.

For horizontal motions the amplitude and period were taken as,

$$
A=\left(A_{\mathrm{N}}^{2}+A_{\mathrm{E}}^{2}\right)^{0.5}, \quad T=0.5\left(T_{\mathrm{W}}+T_{E}\right)
$$

where $\mathrm{N}$ and $\mathrm{E}$ refer to the two orthogonal components (generally north-south and eastwest. If only one horizontal component was available, an increment of 0.1 was added to that magnitude to allow for the likely contribution of the missing component.

\section{JOINT CALCULATION OF MAGNITUDES}

It is normal seismological practice to allow for the response of individual sites when calculating magnitudes. For example, it is standard practice in New Zealand to use empirically determined station corrections [8] when calculationg $\mathrm{M}_{L}$. The statistical technique of Analysis of Variance is convenient for a limited body of data. In this method, the average magnitude of each event and a correction for effects local to the station are calculated simultaneously $[9,10]$. The raw magnitude observation $M_{i j}$ at station $j$ from earthquake $i$ is written:

$$
M_{\mathrm{ij}}=M_{\mathrm{i}}+C_{\mathrm{j}}+e_{\mathrm{i} j}
$$

where $M_{i}$ is the "true" average magnitude, $C$ is the correction for station $j$, and $e_{i j}$ is a random error that combines observational inaccuracy and modelling deficiency.

The presence of the station term $C_{j}$ means that the estimated magnitudes are coupled together. The coupling between two events can be thought of as the number of stations contributing to both, but this is only approximate, as two events will be coupled if they have no station in common but individually have stations in common with a third event. In the data considered here, all events are coupled, but the strength of the coupling varies greatly between events.

There may be complications. As written, the "station" term in equation (4) also includes differences in the average attenuation along the paths to the stations. For a station recording earthquakes in different regions of the world this could be expected to be different for each region. As we are concerned solely with New Zealand events, we can neglect this effect, recognising that it will, however, have a small impact on our estimates. Seismographs at different magnifications and distances will record and report different subsets of the data: low magnification, distant stations will only report the larger events, while high magnification, near stations may be overloaded by these and so only report smaller ones. The number of stations reporting an event generally increases with increasing magnitude. These effects cause two problems. First, there may be an uneven coupling of magnitudes, in that the link between large and small magnitudes is afforded only by stations that record both. The coupling problem is much exacerbated here by changes to the seismograph network with time. We will examine this later, but an example will illustrate the problem.

The earliest two events we considered were largely recorded on Milne seismographs which, except at Melbourne (MEL), recorded no other events (Table 1). Coupling of these events to the rest is thus relatively poor.

The second problem is one of biased sampling. If smaller events are only reported from stations with a high signalto-noise ratio, the sample is biased in favour of higher magnitudes. Conversely, if larger events overload some stations, then the largest amplitudes may tend to be omitted from the sample, leading to a bias towards lower magnitudes.

The first problem is overcome to the extent possible by our method, which reflects the coupling, or lack of it, in the standard error of the estimated magnitude. Thus the inherent uncertainty of a poorly coupled event is reflected in a higher standard error for that event.

The second problem we ignore. There are complex procedures for dealing with it that we believe to be unjustified in the data considered here. There is certainly no evidence for significant biasing downwards of the larger events, which only reach $M_{s}$ 7.8. Possible upward biasing of the 
TABLE 1: STATION MAGNITUDE DATA SETS FOR THE 1901, 1904 AND 1968 EVENTS

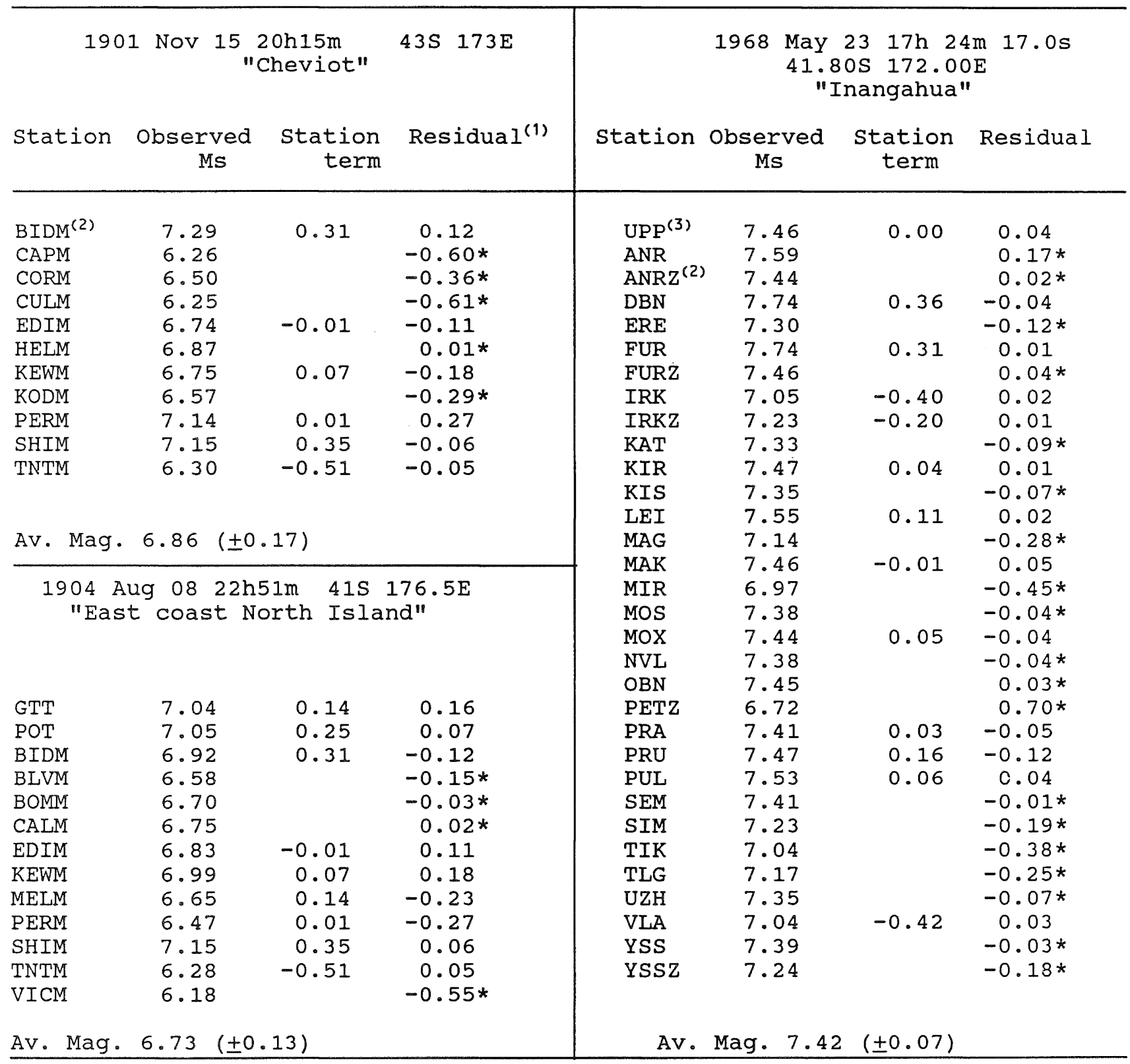

Notes: 1 "Residual" means: (Observed magnitude - Station term - Average magnitude)

24 th character of station code $M$ or $Z$ denotes Milne or vertical component respectively

3 Reference station

* denotes a value not used to compute the average magnitude (because the station reported only one event).

smaller events is a lesser problem. Local magnitude, $M_{1}$, is routinely and reliably calculated for events smaller than about magnitude 6. At this magnitude the two scales approximately coincide, with $\mathrm{M}_{\mathrm{s}}$ gradually falling away with respect to $M_{L}^{s}$ $[5,11]$ at lower magnitudes.

A third problem arises from New Zealand's geographical isolation. Stations reporting
New Zealand's earthquakes are very unevenly distributed around the globe: in particular, there is a disproportionately large number of European stations compared to other regions. The problem is made more complex by being compounded with the first and second problems: the number of European data depends on the size of the event. If one were concerned about assessing the relative sizes of New Zealand events in a global 
catalogue, this would be a major concern, and some sort of weighting scheme would be necessary to diminish the effect of the concentration of European data. However, our goal is to produce a consistent, quantitative ranking of New Zealand events only, and so no such steps have been taken.

In equation (4) the errors $e_{i j}$ are assumed to be independently distributed with common variance $\sigma^{2}, i . e$. there is assumed to be no variation in the precision of the readings between stations. Examination of some magnitude residuals $r_{i j}$

$$
r_{i j}=M_{i j}-\hat{M}_{i}-\hat{C}_{j}
$$

(where the circumflex ' denotes an estimated quantity) at individual stations indicated that this was a satisfactory assumption. It follows that a conventional least-squares solution of the set of equations (4) yields estimates of the standard errors of both the average magnitudes and the station terms.

There is a trivial complication. It can be seen that adding any constant to all the average magnitudes and subtracting the same constant from all the station terms will leave equation (4) unaltered. In other words the "baseline" of magnitudes and station terms are inseparable. It is usual to resolve this problem either by having a reference station for which the station term is fixed at zero (eg Haines, Ref. 8) or by requiring that the sum of all the station terms be zero. We have adopted the first method, choosing as the reference station Uppsala (UPP), which reported 29 of the 69 events for which $M_{s}$ was determined. As it turned out, adopting the second criterion would have made negligible difference to the average magnitudes, as the average of the station terms was -0.03 . Requiring that the average station term be zero would have subtracted an insignificant 0.03 from every magnitude.

A final point. In the collected data a number of stations had reported only a single event. This single reading in effect defines (rather poorly) their station term and the station in fact makes no contribution to the average magnitude of the event. Thus "useful" information is contributed only by stations that have reported at least two events, and there were 81 such stations (but see discussion below).

\section{ANALYSIS OF THE DATA}

Because of the problems attended to in the previous section and in the interests of showing that the final magnitudes were as consistent as possible, a number of experiments were conducted.

First, it was not clear that the station term would be the same for the horizontal and vertical components at a station where examined to ascertain whether the vertical and horizontal data could be combined. At most stations this appeared to be the case, and, at those stations, the horizontal and vertical raw magnitudes were arithmetically averaged and the data re-processed. The effect on the calculated average magnitudes was (gratifyingly) negligible. At six stations, the difference between the vertical and horizontal station term was $\geq 0.2$. Only at TAS (Tashkent) and RIV (Riverview, New South Wales) were the differences statistically significant. However, the distinction between the vertical and horizontal components was retained for these six stations. This increased the effective number of "stations" in the analysis from 81 to 87.

A second, allied problem arose with the Milne data. At some stations, a Milne was replaced by some other instrument. Because of the very different nature of the Milne seismograph and the different formula used to calculate Milne magnitudes (equation 1 ), the distinction between Milnes and other seismographs was retained.

A third concern was allied to the second: other instrumental changes would have taken place during the 87 year period considered that might have had the result of causing the station terms to change with time. One important change known to have had a major effect on the network was the establishment during the 1960's of the World Wide Standard Seismograph Network (WWSSN), featuring $100 \mathrm{~s}$ period Press-Ewing seismometers with $15 \mathrm{~s}$ period galvanometers. In fact, the only station at which a change of instrumentation to Press-Ewings is noted in the International seismological centre catalogues and which reported data from both the pre- and post- WWSSN era was RIV. Therefore RIV was experimentaliy treated as two separate "stations" for the pre- and post- WWSSN era. The station terms for the two "stations" were found to be almost identical, and so the distinction between pre- and post- WWSSN was dropped.

In the calculation of surface wave magnitudes, it is customary not to include data from stations very close (within $20^{\circ}$ angular distance) or very remote (beyond $160^{\circ}$ angular distance). This is done to avoid near-source complications, and amplification due to focussing at $180^{\circ}$. Since many European stations are $160^{\circ}-170^{\circ}$ away from New Zealand, a significant amount of data would be lost by enforcing the $160^{\circ}$ rule. At the same time, as the variation in distance to any station is small, any amplification effect will tend to be amalgamated into the station term. Examination of the magnitude residuals (observed magnitude minus estimated average magnitude) at stations beyond $160^{\circ}$ shows no more scatter than the others, supporting the view that the variation in the amplification with distance is not great. Accordingly, these data have been incorporated into the analysis.

We conclude that the final results are stable to small changes in the estimation process and represent as consistent a set of magnitudes as one can expect to get from such data. 
TABLE 2: NEW ZEALAND EARTHQUARES - SHALLOW EVENTS (h<45 km)

\begin{tabular}{|c|c|c|c|c|c|c|c|}
\hline No. & \multicolumn{3}{|c|}{ Date } & Lat & Iong & Depth & $M_{s}(d M) n$ \\
\hline 1 & 1901 & Nov & 15 & 43 & 173 & 12 & $6.9(0.17) 6$ \\
\hline 2 & 1904 & Aug & 8 & 41 & $176 \frac{1}{2}$ & c. 45? & $6.7(0.13) 9$ \\
\hline 3 & 1911 & Oct & 5 & $39 \frac{1}{2}$ & 177 & $<45 ?$ & $5.3(0.15) 2$ \\
\hline 4 & 1914 & Feb & 8 & 41 & 175 & $<45 ?$ & $4.9(0.15) 2$ \\
\hline 5 & & Oct & 6 & 38 & $178 \frac{1}{2}$ & $<20 ?$ & $6.7(0.08) 8$ \\
\hline 6 & & oct & 28 & 38 & $178 \frac{1}{2}$ & $<20 ?$ & $6.5(0.09) 7$ \\
\hline 7 & 1917 & Aug & 5 & 40.8 & 176 & $<45 ?$ & $6.6(0.08) 9$ \\
\hline 8 & 1922 & Dec & 25 & 43 & 173 & 10 & $6.4(0.08) 7$ \\
\hline 9 & 1929 & Mar & 9 & 43 & $171 \frac{1}{2}$ & $<15$ & $7.1(0.06) 20$ \\
\hline 10 & & Jun & 16 & 41.7 & 172.2 & 20 & $7.8(0.06) 16$ \\
\hline 11 & & Jun & 22 & 42 & 172 & $\leq 20$ & $6.3(0.09) 7$ \\
\hline 12 & 1930 & Feb & 12 & $40 \frac{1}{2}$ & $176 \frac{1}{2}$ & $<45 ?$ & $6.2(0.07) 13$ \\
\hline 13 & 1931 & Feb & 2 & 39.3 & 177 & 30 & $7.8(0.06) 19$ \\
\hline 14 & 1931 & Feb & 8 & 39.2 & 177.5 & $\leq 60 ?$ & $6.3(0.08) 10$ \\
\hline 15 & & Feb & 13 & 39.5 & 177.5 & 30 & $7.3(0.06) 20$ \\
\hline 16 & & Sep & 15 & 45 & 168 & $<60 ?$ & $5.4(0.21) 1$ \\
\hline 17 & 1932 & Mar & 5 & $36 \frac{1}{2}$ & 178 & 30 & $6.0(0.12) 3$ \\
\hline 18 & & May & 5 & $39 \frac{1}{2}$ & $177 \frac{1}{2}$ & $\leq 30$ & $5.9(0.08) 8$ \\
\hline 19 & & Sep & 15 & 38.9 & 177.6 & 30 & $6.9(0.06) 22$ \\
\hline
\end{tabular}

\section{CATALOGUE OF RESULTS}

The results of the above calculations are given in Tables 2 and 3 . In the right-hand column of these tables, together with the magnitude $\left(M_{s}\right)$, we give the standard error (dM) and the number of station magnitudes used for each event $(n)$.

For completeness we also include the station terms and standard errors (Table 4). stations are shown in alphabetical order within each distance range $\left(D^{\circ}\right)$. Eighty seven stations with 2 or more recordings, plus 9 Milnes with only one recording are shown at the median distance of their observations.

\section{COMPARISON WITH MAGNITUDES FROM OTHER} STUDIES

The magnitudes estimated here represent no great change from the previously adopted 
TABLE 2 (continued)

\begin{tabular}{|c|c|c|c|c|c|c|c|}
\hline No. & \multicolumn{3}{|c|}{ Date } & Lat & Long & Depth & $\mathbb{M}_{s}(d M) n$ \\
\hline 20 & 1934 & Mar & 5 & $40 \frac{1}{2} ?$ & $175 \frac{1}{2} ?$ & c. $45 ?$ & $7.6(0.06) 21$ \\
\hline 21 & 1934 & Mar & 15 & 38.9 & 177.2 & $\leq 40$ & $6.4(0.07) 11$ \\
\hline 22 & 1938 & Dec & 15 & 40 & 177 & $<45 ?$ & $5.6(0.11) 4$ \\
\hline 23 & 1942 & Jun & 24 & 40.9 & 175.9 & 15 & $7.2(0.07) 13$ \\
\hline 24 & & Aug & 1 & 41.0 & 175.8 & 43 & $7.0(0.07) 13$ \\
\hline 25 & 1943 & Sep & 22 & 36 & 177 & $<15 ?$ & $6.5(0.09) 6$ \\
\hline 26 & 1945 & Sep & 1 & 47.5 & 166.1 & $<45 ?$ & $7.0(0.07) 12$ \\
\hline 27 & 1956 & Jan & 30 & 37.3 & 177.1 & 10 & $6.4(0.08) 7$ \\
\hline 28 & 1957 & Feb & 22 & 39.2 & 175.2 & $25-40$ & $4.9(0.14) 2$ \\
\hline 29 & 1958 & Jan & 31 & 39.9 & 176.3 & $40 ?$ & $5.2(0.11) 4$ \\
\hline 30 & 1959 & May & 22 & 41.0 & 174.3 & $40 ?$ & $4.9(0.23) 1$ \\
\hline 31 & 1960 & Feb & 3 & 37.4 & 178.2 & 30 & $5.1(0.13) 3$ \\
\hline 32 & & May & 24 & 44.2 & 167.7 & $12-40$ & $6.5(0.08) 9$ \\
\hline 33 & 1961 & Dec & 27 & 41.5 & 176.2 & $10-30$ & $6.5(0.07) 10$ \\
\hline 34 & 1962 & $\operatorname{Jan}$ & 23 & 38.6 & 174.6 & 12 & $4.5(0.20) 1$ \\
\hline 35 & & May & 10 & 41.7 & 171.5 & 12 & $5.9(0.09) 6$ \\
\hline 36 & & oct & 15 & 43.5 & 169.7 & $12-40$ & $5.4(0.16) 6$ \\
\hline 37 & 1963 & Apr & 12 & 38.6 & 176.8 & 20 & $5.7(0.10) 8$ \\
\hline
\end{tabular}

values for most of the important earthquakes. However, there are one or two minor, but significant, differences.

To demonstrate these differences, Table 5 shows the earthquakes with magnitude $>6.7$ as determined herein and the corresponding estimates of Richter's 1958 revision [12] of Gutenberg and Richter's original assessments, and Abe $[13,14]$, who attempted a comprehensive revision and an extension to more modern events of Gutenberg and Richters' surface wave magnitudes. The differences between our magnitudes and
Richter's 1958 values are very small - the average difference is $0.0( \pm 0.05)$ and the magnitudes of the largest three events, Murchison, Napier and Pahiatua, are virtually the same. Abe's magnitudes are systematically smaller by $0.1( \pm 0.04)$. This discrepancy is largely explained by Abe's use of a formula for $\mathrm{M}_{S}$ in which the additive constant is 0.18 smaller than the value of 3.3 in equation (2). Our set of magnitudes thus represents no radical reassessment of larger New Zealand earthquakes. The importance of our set of magnitudes lies in the inclusion of events 
TABLE 2 (continued)

\begin{tabular}{|c|c|c|c|c|c|c|c|}
\hline No. & \multicolumn{3}{|c|}{ Date } & Lat & Long & Depth & $\mathrm{M}_{\mathrm{s}}(\mathrm{dM}) \mathrm{n}$ \\
\hline 38 & 1963 & Dec & 22 & 35.1 & 173.5 & 12 & $4.4(0.20) 1$ \\
\hline 39 & 1964 & Mar & 8. & 44.3 & 167.7 & 12 & $5.8(0.09) 10$ \\
\hline 40 & 1966 & Mar & 4 & 38.8 & 178.1 & 20 & $5.8(0.08) 8$ \\
\hline 41 & & Apr & 23 & 41.8 & 174.7 & 20 & $5.6(0.10) 7$ \\
\hline 42 & 1968 & May & 23 & 41.8 & 172.0 & 13 & $7.4(0.07) 13$ \\
\hline 43 & & Sep & 25 & 46.7 & 166.5 & 10 & $6.2(0.08) 7$ \\
\hline 44 & & Nov & 1 & 41.7 & 175.1 & $20-30$ & $5.0(0.13) 3$ \\
\hline 45 & 1971 & Aug & 13 & 42.2 & 172.3 & $5-12$ & $5.5(0.08) 7$ \\
\hline 46 & 1972 & $\operatorname{Jan}$ & 8 & 37.6 & 175.7 & $5-12$ & $5.0(0.14) 2$ \\
\hline 47 & 1974 & Sep & 20 & 44.4 & 168.0 & $12-40$ & $5.3(0.11) 4$ \\
\hline 48 & & Nov & 5 & 39.5 & 173.5 & $12-20$ & $5.4(0.10) 5$ \\
\hline 49 & 1976 & May & 4 & 44.7 & 167.4 & $12-30$ & $6.4(0.07) 14$ \\
\hline 50 & 1976 & Dec & 5 & 38.2 & 175.5 & 5 & * \\
\hline 51 & 1977 & Jan & 18 & 41.8 & 174.6 & 36 & $5.9(0.08) 8$ \\
\hline 52 & 1978 & Jan & 18 & 42.5 & 172.6 & 12 & $5.2(0.14) 2$ \\
\hline 53 & 1979 & oct & 12 & 46.7 & 166.0 & $12 \pm 5$ & $7.2(0.08) 10$ \\
\hline 54 & 1983 & Dec & 14 & 38.4 & 176.3 & 5 & $4.6(0.14) 2$ \\
\hline 55 & 1984 & Jun & 24 & 43.6 & 170.6 & 5 & $6.1(0.08) 9$ \\
\hline 56 & 1985 & Jul: & 19 & 38.8 & 177.4 & $31 \pm 1$ & $5.9(0.07) 16$ \\
\hline 57 & 1987 & Mar & 2 & 37.9 & 176.8 & 8 & $6.6(0.08) 21$ \\
\hline
\end{tabular}

* No surface waves observed 
TABLE 3: NEW ZEALAND EARTHQUAKES - INTERMEDIATE DEPTH EVENTS (h > $45 \mathrm{~km}$ )

\begin{tabular}{|c|c|c|c|c|c|c|}
\hline No. & \multicolumn{2}{|c|}{ Date } & Lat & Long & Depth & $M_{s}(d M) n$ \\
\hline 58 & 1921 & Jun 28 & 39.3 & 176.4 & 80 & $6.4(0.09) 6$ \\
\hline 59 & 1927 & Feb 25 & 38 & 178 & 60 & $6.2(0.08) 9$ \\
\hline 60 & 1931 & Sep 21 & 37 & 178 & 80 & $6.1(0.13) 3$ \\
\hline 61 & 1932 & Jul 20 & 40 & 174 & 60 & $5.1(0.20) 1$ \\
\hline 62 & 1938 & Dec 16 & 45 & 167 & 60 & $7.0(0.06) 18$ \\
\hline 63 & 1943 & Aug 2 & 46.1 & 167 & $50-80$ & $6.6(0.07) 13$ \\
\hline 64 & 1951 & Apr 23 & 37.6 & 177.8 & $80-125$ & $5.7(0.14) 2$ \\
\hline 65 & 1960 & Feb 21 & 423 & 173.1 & 49 & $5.4(0.10) 5$ \\
\hline 66 & 1965 & Jun 15 & 37.9 & 177.5 & 65 & $5.3(0.10) 7$ \\
\hline 67 & 1973 & $\operatorname{Jan} 5$ & 39.0 & 175.3 & 160 & $6.3(0.08) 9$ \\
\hline 68 & 1975 & Jan 4 & 40.9 & 174.9 & 80 & $4.6(0.14) 2$ \\
\hline 69 & 1975 & Jun 10 & 40.3 & 176.1 & $\begin{array}{c}50 \\
(\text { or } 33)\end{array}$ & $5.3(0.14) 2$ \\
\hline 70 & 1988 & Jun 3 & 45.1 & 167.2 & 57 & $6.7(0.10) 11$ \\
\hline
\end{tabular}

that were hitherto without an instrumentally assessed magnitude, and one or two events with small but important differences.

\section{IMPORTANT EARTHOUARES}

It is beyond the scope of this paper to discuss every event for which our magnitude is different from that previously adopted. However, because of their importance, a few events are worthy of mention.

The 1901 Cheviot and 1904 East Coast North Island earthquakes (Table 1), and the 1914 East Cape earthquakes are important because the usually adopted magnitudes are not instrumental but based on macroseismic data. All were assessed as $M \geq 7$ by Smith and Berryman [4]. In particular, they assigned the 1904 and 1914 events $M=7.5$. The 1914 event is the largest to have occurred north of Gisborne in historical times. Its reassessment at 6.7 must have significant impact on the assessment of seismic hazard in this region.

The magnitude of the 1904 event is largely determined from Milne seismographs and that of the 1901 one is wholly so (Table 1). Their poor coupling to the rest of the data is reflected in relatively large standard errors for these events. Moreover, there is a possibility of systematic error due to a different magnitude formula being used for Milne data (equation 1), although equations (1) and (2) seem to give consistent $M_{s}$ values over the full range of distances [5]. However, as the variation of distances between the earthquakes and any station is very small, any error in the distance correction term will be incorporated into 
TABLE 4: STATION TERMS AND STANDARD ERRORS FOUND IN STATION CORRECTION ANALYSIS OF $M_{S}$ DATA SET.

\begin{tabular}{|c|c|c|c|c|}
\hline & station & $\begin{array}{c}\text { Station } \\
\text { Term }\end{array}$ & $\begin{array}{c}\text { Standard } \\
\text { Error }\end{array}$ & $\begin{array}{c}\text { No. of } \\
\text { Obs }\end{array}$ \\
\hline \multicolumn{5}{|l|}{$20^{\circ}$} \\
\hline & RIV & -0.05 & 0.048 & 54 \\
\hline & RIVZ & -0.32 & 0.051 & 38 \\
\hline & MEL & -0.04 & 0.076 & 11 \\
\hline & MELM & 0.14 & 0.094 & 7 \\
\hline & SUV & -0.01 & 0.117 & 4 \\
\hline & SUVM & 0.08 & 0.129 & 3 \\
\hline $30^{\circ}$ & ASPZ & -0.08 & 0.158 & 2 \\
\hline & HLI & 0.02 & 0.121 & 5 \\
\hline \multicolumn{5}{|l|}{$40^{\circ}$} \\
\hline & PERM & 0.01 & 0.197 & 2 \\
\hline & $S B A$ & 0.06 & 0.108 & 5 \\
\hline \multicolumn{5}{|c|}{-0.18} \\
\hline & \multicolumn{4}{|c|}{-0.04} \\
\hline & CORM & -0.36 & 0.258 & 1 \\
\hline & $\mathrm{GZH}$ & -0.16 & 0.151 & 2 \\
\hline & MATZ & -0.19 & 0.150 & 2 \\
\hline & OSA & 0.00 & 0.107 & 4 \\
\hline \multicolumn{5}{|c|}{0.104} \\
\hline 90 & BJI & -0.23 & 0.096 & 6 \\
\hline & BKSZ & 0.14 & 0.151 & 2 \\
\hline & GYA & -0.37 & 0.151 & 2 \\
\hline & KMI & -0.17 & 0.112 & 4 \\
\hline & LPB & 0.01 & 0.073 & 11 \\
\hline & NNAZ & -0.48 & 0.158 & 2 \\
\hline & PASZ & -0.38 & 0.158 & 2 \\
\hline \multicolumn{5}{|l|}{$100^{\circ}$} \\
\hline & ALQZ & -0.08 & 0.131 & 3 \\
\hline & $\mathrm{BMO}$ & -0.52 & 0.158 & 2 \\
\hline & $\mathrm{BMOZ}$ & -0.23 & 0.133 & 3 \\
\hline & BTO & -0.20 & 0.125 & 3 \\
\hline & CALM & 0.02 & 0.233 & 1 \\
\hline & CAPM & -0.60 & 0.258 & 1 \\
\hline & CULM & -0.61 & 0.258 & 1 \\
\hline & GOLZ & -0.18 & 0.158 & 2 \\
\hline & HYD & 0.02 & 0.084 & 7 \\
\hline & KOD & 0.01 & 0.097 & 5 \\
\hline & KODM & -0.29 & 0.258 & 1 \\
\hline & $\mathrm{LZH}$ & -0.19 & 0.152 & 2 \\
\hline & TFOZ & -0.28 & 0.131 & 3 \\
\hline & UBO & -0.05 & 0.120 & 4 \\
\hline & VICM & -0.55 & 0.233 & 1 \\
\hline
\end{tabular}


TABLE 4: (continued)

\begin{tabular}{|c|c|c|c|c|}
\hline & station & $\begin{array}{l}\text { Station } \\
\text { Term }\end{array}$ & $\begin{array}{c}\text { Standard } \\
\text { Error }\end{array}$ & $\begin{array}{l}\text { No. of } \\
\text { Obs }\end{array}$ \\
\hline \multicolumn{5}{|l|}{$110^{\circ}$} \\
\hline & BOM & -0.07 & 0.061 & 17 \\
\hline & BOMM & -0.03 & 0.233 & 1 \\
\hline & $\mathrm{CPO}$ & 0.01 & 0.117 & 4 \\
\hline & IRK & -0.40 & 0.090 & 6 \\
\hline & IRKZ & -0.20 & 0.121 & 3 \\
\hline & WMO & -0.17 & 0.158 & 2 \\
\hline \multirow{2}{*}{\multicolumn{5}{|c|}{$120^{\circ}$}} \\
\hline & & & & \\
\hline & TAS & -0.20 & 0.074 & 11 \\
\hline & TASZ & -0.68 & 0.123 & 3 \\
\hline & TNTM & -0.51 & 0.197 & 2 \\
\hline \multicolumn{5}{|l|}{$130^{\circ}$} \\
\hline $140^{\circ}$ & SVE & -0.13 & 0.082 & 8 \\
\hline & BAK & 0.40 & 0.082 & 8 \\
\hline & HLW & 0.45 & 0.107 & 4 \\
\hline & HLWM & 0.01 & 0.258 & 1 \\
\hline & KJFZ & 0.12 & 0.158 & 2 \\
\hline & KUC & 0.04 & 0.092 & 6 \\
\hline & MBO & 0.59 & 0.149 & 2 \\
\hline & UPP & 0.00 & Reference & 29 \\
\hline & BEO & 0.09 & 0.076 & 9 \\
\hline & KIR & 0.04 & 0.077 & 9 \\
\hline & $\mathrm{KRAZ}$ & 0.07 & 0.158 & 2 \\
\hline & LEM & -0.03 & 0.146 & 2 \\
\hline & MAK & -0.01 & 0.149 & 2 \\
\hline & NURZ & 0.51 & 0.131 & 3 \\
\hline & PUL & 0.06 & 0.078 & 9 \\
\hline & SLLZ & 0.12 & 0.158 & 2 \\
\hline \multicolumn{3}{|l|}{$160^{\circ}$} & 0.125 & 3 \\
\hline & BUD & 0.15 & 0.076 & 9 \\
\hline & GRFZ & 0.24 & 0.151 & 2 \\
\hline & HAM & 0.35 & 0.081 & 8 \\
\hline & JEN & -0.05 & 0.070 & 11 \\
\hline & $\mathrm{KHC}$ & 0.05 & 0.124 & 3 \\
\hline & LEI & 0.10 & 0.073 & 10 \\
\hline & LJU & 0.14 & 0.120 & 3 \\
\hline & MOX & 0.05 & 0.078 & 9 \\
\hline & POT & 0.25 & 0.127 & 3 \\
\hline & PRA & 0.03 & 0.071 & 11 \\
\hline & PRU & 0.16 & 0.082 & 8 \\
\hline & WIE & 0.08 & 0.089 & 6 \\
\hline
\end{tabular}


TABLE 4: (continued)

\begin{tabular}{|c|c|c|c|c|}
\hline & station & $\begin{array}{c}\text { Station } \\
\text { Term }\end{array}$ & $\begin{array}{c}\text { standard } \\
\text { Error }\end{array}$ & $\begin{array}{l}\text { No. of } \\
\text { Obs }\end{array}$ \\
\hline $\begin{array}{l}165^{\circ} \\
170^{\circ} \\
175^{\circ}\end{array}$ & $\begin{array}{l}\text { BIDM } \\
\text { BRU } \\
\text { DBN } \\
\text { EDIM } \\
\text { EGE } \\
\text { FUR } \\
\text { GTT } \\
\text { KEW } \\
\text { KEWM } \\
\text { POL } \\
\text { STR } \\
\text { STU } \\
\text { TRI } \\
\text { ALG } \\
\text { PAR } \\
\text { SHIM }\end{array}$ & $\begin{array}{r}0.31 \\
0.23 \\
0.36 \\
-0.01 \\
-0.13 \\
0.31 \\
0.14 \\
0.36 \\
0.07 \\
0.03 \\
0.23 \\
0.10 \\
-0.39 \\
0.19 \\
0.30 \\
0.35\end{array}$ & $\begin{array}{l}0.197 \\
0.068 \\
0.053 \\
0.197 \\
0.108 \\
0.151 \\
0.078 \\
0.125 \\
0.197 \\
0.125 \\
0.076 \\
0.122 \\
0.152 \\
0.085 \\
0.061 \\
0.197\end{array}$ & $\begin{array}{r}2 \\
12 \\
27 \\
2 \\
4 \\
2 \\
9 \\
3 \\
2 \\
3 \\
9 \\
3 \\
2 \\
\\
7 \\
18 \\
2\end{array}$ \\
\hline
\end{tabular}

Average Station Term: -0.027

station term and this will not cause a systematic error. Similarly, a base-line error between the two formulae will also be largely absorbed into the station terms. We conclude that the magnitudes calculated for these events are acceptably consistent with the rest of the set.

Of the earthquakes with magnitudes greater than were previously assessed, the 1968 Inangahua event, estimated at $M_{s}=7.4$, is the most important. Abe $[13,14]$ and Smith $\&$ Berryman [4] both give it $M=7.1$. It would appear that this discrepancy is mostly due to the difference of 0.18 in the magnitude formulae already noted. Nonetheless, it remains that the Inangahua earthquake, at $\mathrm{M}_{\mathrm{s}}=7.4$ (Table 1) was significantly larger than has been appreciated. Moreover, the magnitude of the 1929 Murchison event is now estimated to be 7.8 compared with 7.6 given by Smith and Berryman. This has implications both for the assessment of seismic hazard and seismic deformation in the north-western South Island. Not only has this region been subject to rather more severe earthquakes than assumed in seismicity models, but the Inangahua earthquake is an important benchmark event in the association of macroseismic effects and magnitude. For example, Eiby [15] has previously judged the
1848 Marlborough earthquake to be magnitude 7.1 by comparison of its isoseismal map with those for other events, among them Inangahua. Revision of the Inangahua magnitude upward to 7.4 could have a similar effect on the magnitude assessment of the 1848 event.

\section{ACRNOWLEDGEMENTS}

Much of the data set was not available in New Zealand and this necessitated visits by the senior author to Australia and England in order to obtain sufficient data. Acknowledgement is made of the financial support of the DSIR which made this possible, and the authors wish to express their gratitude to friendly co-operation during this trip of the following people and organisations: $M$ Leiba and $K$ McCue (Australian Seismological Centre, Canberra); $\mathrm{N}$ Ambraseys (Imperial College, London); $R$ Adams and $A$ Hughes (International Seismological Centre, Thatcham, England).

We also wish to thank DSIR colleagues for helpful reviews of this paper, namely $J$ Haines, $G$ McVerry and $D$ Rhoades. In addition we thank our colleagues $\mathrm{H}$ Anderson, $B$ Ferris, M Reyners and $T$ Webb for kindly helping by providing some of the information used in this study. 
TABLE 5. COMPARISON OF MAGNITUDE DETERMINATIONS: MAGNITUDES $\geq 6.7$

\begin{tabular}{|c|c|c|c|c|}
\hline Event & Year & Magnitude & $\begin{array}{c}\text { Richter } \\
(1958) \\
\text { (Ref 12) }\end{array}$ & $\begin{array}{c}\text { Abe }(1981, \\
1983) \\
\text { (Refs } 13,14)\end{array}$ \\
\hline Cheviot & 1901 & 6.9 & - & 6.8 \\
\hline East Coast NI & 1904 & 6.7 & - & 6.9 \\
\hline East Cape & 1914 & 6.7 & $6 \frac{1}{2}$ & - \\
\hline Arthur's Pass & 1929 & 7.1 & 6.9 & - \\
\hline Murchison & 1929 & 7.8 & 7.8 & 7.6 \\
\hline Napier & 1931 & 7.8 & 7.9 & 7.8 \\
\hline $\begin{array}{l}\text { Napier } \\
\text { Aftershock }\end{array}$ & 1931 & 7.3 & 7.3 & 7.1 \\
\hline Wairoa & 1932 & 6.9 & 6.8 & - \\
\hline Pahiatua & 1934 & 7.6 & 7.6 & 7.5 \\
\hline Fiordland & 1938 & 7.0 & 7.0 & 6.9 \\
\hline Wairarapa Jun 24 & 1942 & 7.2 & 7.3 & 7.0 \\
\hline Wairarapa Aug 1 & 1942 & 7.0 & 7.3 & 6.9 \\
\hline Puysegur Bank & 1945 & 7.0 & - & - \\
\hline Inangahua & 1968 & 7.4 & $\mathrm{NC}$ & 7.1 \\
\hline Puysegur Bank & 1979 & 7.2 & NC & 7.2 \\
\hline Te Anau & 1988 & 6.7 & $\mathrm{NC}$ & NC \\
\hline
\end{tabular}

Average difference $\quad M-R=0.0$

Average difference $\quad M-A=0.1$ 


\section{REFERENCES}

1. Gutenberg, B and Richter, C F (1949) "Seismicity of the earth and associated phenomena", Princeton University Press.

2. Eiby, G A (1986) "An annotated list of New Zealand earthquakes:, NZ Jnl of Geology and Geophysics, 11, 630-647.

3. Smith, W D (1978) "Spatial distribution of felt intensities for New Zealand earthquakes", NZ Jnl of Geology and Geophysics, 21, 293-311.

4. Smith, W D and Berryman, K R (1983) "Revised estimates of earthquake hazard in New Zealand", Bulletin NZ National Soc for Earthq Eng, 16, 259-272.

5. Dowrick, D J "Magnitude reassessment of New Zealand earthquakes" (in preparation).

6. Ambraseys, N N and Melville, C P (1982) "A history of Persian earthquakes", Cambridge University Press.

7. Vanek, J, Zatopek, A, Karnik, V, Kondorskaya, N, Riznichenko, Y, Savarenski, E, Solviev, S and Shebalin, $\mathrm{N}$ (1962) "Standardization of magnitude scales", Izvest Acad Sci USSR, Geophys Ser 2: 108 .
8. Haines, A J (1981) "A local magnitude scale for New Zealand earthquakes", Bull Seism Soc Am, 71: 275-294.

9. Bolt, B A and Freedman, $\mathrm{H}$ V (1968) "Group Analysis of Variance for Earthquake Location and Magnitude", Nature, 217: 47-48.

10. Smith, E G C and Oppenheimer, C M M (1989) "The Edgecumbe Earthquake Sequence: 1987 February 21 to March 18", NZJ Geol Geophys, 32: 31-42.

11. Smith, E G C (1990, in prep.) "What is $M_{L}$ ? A comparison of the local and surface wave magnitude scales".

12. Richter, C F (1958) "Elementary Seismology". 768 pp. W H Freeman, San Francisco.

13. Abe, K (1981) "Magnitudes of large shallow earthquakes from 1904 to $1980 "$ ", Phys. Earth Planet. Interiors, 27: 7292 .

14. Abe, K (1983) "Revision of magnitudes of large shallow earthquakes, 1897-1912", Phys. Earth Planet, Interiors, 33: 1-11.

15. Eiby, G A (1980) "The Marlborough Earthquake of 1848", DSIR Bulletin 225, $82 \mathrm{pp}$. 